\title{
Alegoria: Modo de Ver, Modos de Usar*
}

\section{Luiz Guimarães Monforte \\ Giorgio Giorgi Jr.}

\section{Resumo}

Rascunho de leitura de três manifestações de procedimentos alegóricos nos campos das artes plásticas e do design.

Abstract

An overview on three allegoric proceedings in the field of design and visual arts. 


\section{Introdução}

Este trabalho transita pela intersecção entre rudimentos da semiótica e o significado usual do termo alegoria. Permitimo-nos, de início, repassar alguns conceitos básicos precavendo-nos contra eventuais confusões de natureza terminológica.

Para Charles S. Peirce, idealizador da semiótica, "signo é tudo aquilo que, em certa medida e para certos efeitos, representa alguma coisa para alguém" Assim colocada, a noção de signo está no cerne do estudo de todo e qualquer tipo de linguagem (a própria idéia de linguagem comfundindo-se com a de sistema ordenado de signos).

Contudo, o alcance do conceito de signo é ainda maior. Para Peirce, tanto a percepção de qualquer coisa ou evento, bem como a possibilidade de elaboração sobre o percebido, são processos mediados, ou seja, que se estruturam através de relações entre signos. Aliás, cada signo inaugura um processo relacional, já que o significado de um signo é outro signo.

Relevante, também, é a classificação dos signos em relação a seu objeto, onde Peirce atualiza o conceito de eixos relacionais, formulado anteriormente por David Hume. De acordo com esta classificação, um signo será um ícone, quando mantiver com seu objeto uma relação por similaridade (uma foto, um desenho, um gráfico). Será um índice, quando essa relação for por contigüidade de fato, ou seja, quando envolver uma espécie de corpo a corpo entre signo e objeto luma pegada, uma cicatriz, a pista de um crime). Será um símbolo, quando tal relação for por contigüidade mediada por uma convenção (uma nota de US\$100, a bandeira de um país, a marca de uma empresa).

Isto posto, vamos ao que interessa. De acordo com o "Aurélio" alegoria consiste, entre outras coisas, na "exposição de um pensamento sob forma figurada (...), fiç̧ão que representa uma coisa para dar idéia de outra (...)" Contudo, se compararmos este modo de abordar a alegoria com o conceito de signo em Peirce, facilmente concluiremos que todo signo (e, conseqüentemente, toda linguagem) mantém uma relação "alegórica" com seu objeto. Todo signo é, em certa medida, "figuração" (particularmente no âmbito das linguagens preponderantemente "icônicas" tais como as artes plásticas, a música, etc.). Talvez, o mais razoável fosse entender a linguagem alegórica como fruto da consciência da "figuração" implícita em todo tipo de processo sígnico (uma imposição do "sistema"...). Em outras palavras, uma elaboração a partir das possibilidades abertas pela condição representativa do signo.

A partir desta constatação, fica mais fácil compreender porque a alegoria freqüentemente tem sido entendida como um procedimento de "segunda categoria", quando comparada ao procedimento "simbólico" É que a todo o instante a alegoria (do grego alos, outro, e agorein, falar) deixa explícita a incompletude do signo.

Não se trata de discordar de Peirce, quando este considera o símbolo como sendo um signo que tende a ser mais elaborado, uma vez que foi testado e homologado pelo uso. Trata-se, isto sim, de reafirmar que até mesmo os processos simbólicos são vulneráveis à "ilusão da contigüidade" diagnosticada por Décio Pignatari, assim como todos os processos, humanos ou não, parecem estar submissos à precaried ade que aflora da abordagem contingencial proposta pela física, a partir da virada do século. 
Por este caminho, fica mais fácil compreender a reabilitação (enquanto procedimento) da alegoria na época moderna, particularmente a partir das reflexōes de $W$. Benjamin. Tal reabilitação parece apoiar-se no caráter essencialmente icônico (mesmo quando tende á "bricolagem") da alegoria. Para Peirce, o ícone opera na raia da "mera possibilidade", transitando com mais desenvoltura neste universo de complexidade e incerteza.

1. Luiz G. Monforte.

O retábulo do descobrimento. 1992. Eletrografia. $120 \times 220 \mathrm{~cm}$.

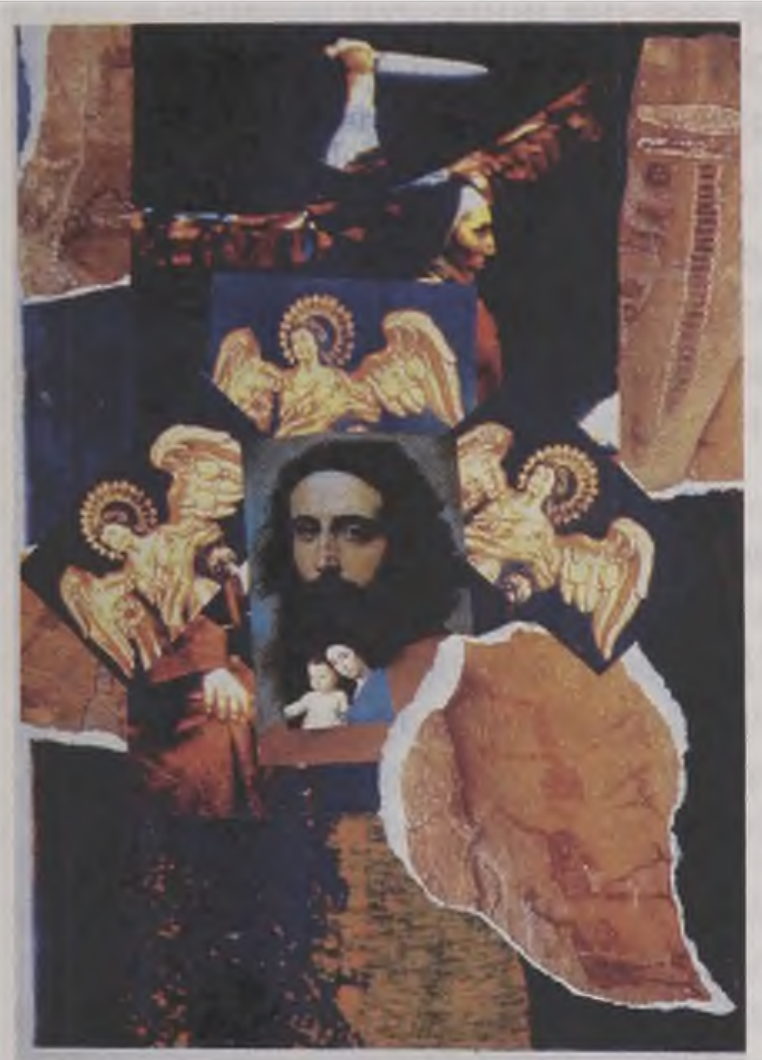

2. Achille Castiglioni.

Taraxacum. Luminária suspensa com luz direta e refletida, corpo icosaédricoem alumínio polido, 60/ 120/200 lâmpadas "Globolux" de 25/40 W. Produção Flos, 1988.
3. Fabio Falanghe e Giorgio Giorgi Jr. zoom-zoom. Protótipo, 1993. Projetor vertical com luz direta, corpo em aluminio anodizado, lentes em vidro e suportes em pvc. Lâmpada halógena com refletor dicrótico, $50 \mathrm{~W} 12 \mathrm{~V} .150 \times 30 \mathrm{~cm}$.

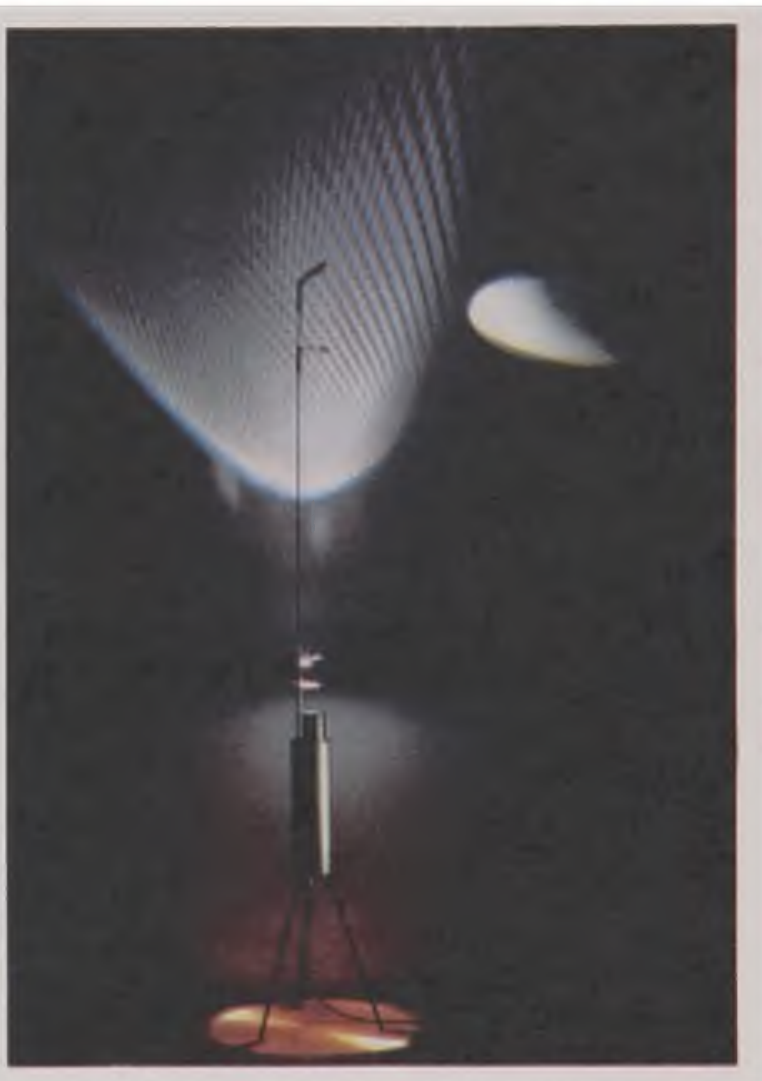

\section{Leituras}

\section{Uma alegoria}

Julgo apropriado anexar a esta introdução alguns trechos do texto "Uma alegoria", elaborado para efeito de avaliação do curso Ambiente e Comunicação, ministrado pelo professor Décio Pignatari no segundo semestre letivo de 1992, por constituir-se do ponto de partida que estimulou minhas reflexões sobre o tema no presente curso, as quais redundaram na identificação de duas visões alegóricas: uma amplificada, aberta, e sua contrapartida.

\section{EL RETABLO DEL DESCUBRIMIENTO - O RETÁBULO DO DESCOBRIMENTO.}

O trabalho objeto desta leitura, "Retábulo do Descobrimento" (Fig. 1), é fruto de minha estada, em setembro de 1992, no laboratório de tecnologias de imagem do Museu Internacional de Eletrografia - MIDE, da Universidade Castilla-La Mancha, na cidade de Cuenca, Espanha.

... Como material básico de trabalho, dispunha dos registros fotográficos, realizados sobre as pinturas rupestres dos sítios arqueológicos do Nordeste 
brasileiro. Imagens que me pareciam pertinentes de serem utilizadas na construção daquele trabalho, por serem a própria negação do tema do descobrimento, uma vez que as mesmas, têm datação comprovada superior há vinte mil anos...

... Face às associações estimuladas pelo material imagético de base, concluí, ser crítico e conflitante o teor que desejava imprimir ao resultado final. Tratava-se de um material "terroso" Uma projeção enigmática e simbólica da terra americana. Imaginário gráfico de inexistente chave léxica, compatível em obscurantismo com o ideário do colonizador sobre a "nova terra"...

... Na etapa seguinte, busquei uma espécie de arquétipo gráfico de época, que funcionasse como uma espécie de tradutor da cultura espanhola, e principalmente caracterizasse a inquisitiva religiosidade da qual era impregnado o colonizador espanhol. Encontrei-a na revista de bordo que me entreteve durante o vôo à Espanha. Justificava o guardado, o caprichoso artigo ilustrado sobre a pintura barroca de Jose de Ribera, "El Españoleto" pintor nascido em 1591, na localidade valenciana de Jativa...

... O barroco de Ribera que pinçamos, era dotado de um cromatismo suave, não raro amparado por um fundo celestial, opos to ao das imagens terrosas, amareladas e laranjas, dos sítios arqueológicos. Fatores que não só dotaram a composição final de dialético ritmo cromático, como também determinaram a partição de seus planos.

O acervo "riberano" nos apontou também uma direção composicional verticalizada e ascendente, como uma espécie de altar. Para compô-lo, selecionamos as pinturas "São Paulo" e "Madona com menino" - (Pai e Filho). Faltava então, o Espírito Santo para completar a mímese da tríade comandante dos princípios apostólicos romanos. O rebatimento da imagem de um anjo, coletada numa publição de teor sacro, solucionou a questão...

Pai, Filho e Santo Espírito, assentados sob uma área de convergência ótica do plano, foram arranjados em forma de cruz, símbolo máximo da cristandade, e figura dominante de qualquer ritual cristão. A "mancha gráfica" reservada ao Todo Poderoso, serve de nicho/abrigo ao Filho e expande-se por um resplendor/espécie de escudo, formado pelo rebatimento da imagem de guarda do Espírito Santo.

Este conjunto flutua sobre um fundo azul escuro, alusão ao celeste, ou mesmo sem muito esforço, aos "mares nunca dantes navegados". Afinal, trata-se de um altar, e via de regra este está contido numa "nave"

Na luminosidade "votiva" (na verdade, uma procissão de miríades), localizada no centro inferior do pano de fundo, a evocação das coisas terrenas, via de trânsito daquilo que do interior da "nave" se vê: invasores, frágeis e explosivos recortes do Novo Mundo, e toda a sua carga de imprevisibilidades, o novo em estado latente, detonador da inevitável e feroz desorganização que sempre acarreta.

o conflitọ estava concluído. Faltava, no entanto, o epílogo. Um ponto de transição figurativa, que transportasse aos dias de hoje à dimensão histórica do descobrimento, como a temos. Faltava ainda, algum tipo de elemento que personificasse o relato do vencedor. O herói.

Encontrei-o na figura de uma monja (também extraída da revista de bordo), de quem a postura não deixa margem à dúvida com relação a suas ferozes intenções, as quais culminam no brilho do punhal, com o qual se lança sobre o Novo Mundo. Para ela, a palavra, bem como as intençōes divinas, ainda que a toque de lâmina, haveria de ser imposta, parece dizer... 
A localização da monja segue os moldes da tradição originariamente espanhola de construção dos retábulos, nos quais os lavores e painéis pintados estão localizados atrás ou acima dos altares...

...Trata-se de um jogo de arquétipos na construção de um discurso expressivo sobre a dominância histórica do herói/vencedor, e valores culturais que impõe ao vencido. Um quase comentário antropológico...

\section{Do outro lado do espelho}

Os sentidos alegóricos identificados como abertos e fechados, são na realidade, faces de uma moeda só; identificam-se à medida e modo de abrangência com que se queira circunscrever o tema. O primeiro, de teor aberto, é de ordem retórica estruturalizante, apontando à figura um direcionamento substitutivo, representacional, atrelada, de certa forma, à cartografia traçada por Charles S. Peirce em sua teoria dos signos. Aqui, sob tal ponto de vista, até mesmo nossas funções denominativas podem ser admitidas como fenômeno alegórico.Tópico, creio, precisamente delineado no bojo inicial deste esforço conjunto.

Do outro lado do espelho, temos a alegoria enquanto morfologia, fórmula, enquanto bula atrelada a historicidade e seus ciclos, caso do "Retábulo" no qual a composição, de afinado teor piramidal nos remete à pintura renascentista, da qual derivam o opulento e torneado barroco e a dinâmica maneirista.

No renascimento - época marcada pela volta aos moldes clássicos de arte grega e romana e da descoberta técnica da perspectiva - podemos identificar um conceito alegórico "fechado" como o descrevemos acima, isto é, ancorado na potencialidade simbólica de um tempo. Aqui cabe invocar, como instrumento de navegação ilustrado, a obra gráfica dos mestres alemães Dürer e Cranach, participantes diretos do renascimento, e do flamengo Van Eyck.

O ideário renascentista, tem sua primeira morada em Florença, na Itália, nas primeiras décadas do século 15, e difunde-se por toda a Europa até meados do século 16. Dele proliferaram conceitos que até hoje ainda perduram, como o de que o projeto mais ainda que sua execução, era o constituinte da obra de arte, e de que sua história era singular, uma história dos indivíduos que a ela se dedicaram.

"Reconhecer a arte do renascimento, é dizer, acima de tudo, distinguir os modos expressivos dos vários artistas. Este conceito, o da arte como resultado individual ainda hoje é válido. De resto, são atualmente, muitos os conceitos, atitudes e terminologia renascentistas ainda em uso. $O$ significado que damos à palavra 'arte' a subdivisão dessa mesma arte em artes maiores e menores; a distinção entre o arquiteto, responsável pela forma de um edifício, e o engenheiro, que responde pela técnica; a enraizada convicção de que um quadro ou uma estátua devem "reproduzir" qualquer coisa, e, aquela ainda mais tenaz, da existência de uma regra para distinguir matematicamente entre $\circ$ belo e 0 horrendo, tudo isto tem origem no renascimento." (Conti, Flavio - Come riconoscere l'arte rinascimentale, Milão, Rizzoli Editore,1978).

O período renascentista também é permeado pelo espírito ardente e plúmbeo de Saturno, expresso no pensamento reformista de Martinho Lutero, o qual, encontra terreno fértil nesta esfera de comportamento de transição onde a visão do mundo alicerçada na fé passa a ser substituída pela que se fundamentava na razão.

O céu e a terra, é dizer, o mito e o homem, via reforma, passam a confrontar-se. $E$, em decorrência deste processo, o horizonte do habitual passa a ser questionado. 
Transitando, porém, pelos grilhões da Santa Inquisição, os quais bradiam a possibilidade de imobilismo a todo o aventureiro que ousasse ir além das fronteiras estabelecidas pela igreja católica.

\section{Hiroshima - Carandiru - Vietnã - Sarajevo - Candelária}

Nesta atmosfera conflitante, a emergência do "sussurro" o qual objetivamente constitui-se no sumo da alegoria: jogo de estatuto complexo, dinâmico e desvinculado de qualquer referência técnica, estilística ou teórica. Estratégia de emergência, "carnavalização" de teor profuso, onde todos os seus elementos parecem funcionar de forma a dissimular, diluir a mensagem subversa à qual se remete. Código mediado por chave léxica barroca, operacionalizadora da disfunção do tempo, para dele extrair o mapa. Discurso da ineficiência do artesanal quase adormecido. Recorte de um horizonte ultrapassado. Testemunho explanativo da "viagem"

A consciência do ser alegórico é antes de mais nada uma consciência cíclica que aflora em tempos de crise, como se fosse um arquétipo (como o define Carl Jung). Assim posto, em O retábulo do descobrimento, concebido objetivamente como uma reflexão sobre o drama sangrento da conquista do continente americano, pode residir também um reflexo do "discurso" do um só. A mônada. O HORROR!

\section{Alegoria Tecnológica}

Em 1988, Flos (provavelmente disposta a não mais abrir mão de um poderoso nicho de mercadol confia a Achille Castiglioni a incumbência de projetar um lustre. Desafio considerável se compararmos a tipologia do lampadário tradicional com a imagem que Flos construiu ao longo de três décadas de existência. Qual poderia ser a contrapartida contemporânea de um objeto que, em certa medida, é paradigmático de técnicas, valores e costumes pré-industriais? "Taraxacum" (Fig. 2) aponta uma das saídas possíveis, operando uma espécie de tradução plástico-tecnológica da tradição.

Mesmo considerando impossível dissociar a idéia de lustre da de alto impacto visual, Castiglioni descarta de cara o recurso a adereços (pingentes, etc.), os quais resultariam "indigestos" a si próprio e ao fabricante. Agindo assim, descarta simultaneamente o procedimento alegórico mais convencional (o qual privilegia relações por contigüidade). A lâmpada incandescente é entendida como síntese industrial da vela e do vidro artesanal. Não qualquer lâmpada, mas aquela que mais explícita as próprias "vísceras" a fim de, ligando fio a pavio, aproximar-se plasticamente da qualidade de sensação da chama, ora filtrada, ora refletida pelo vidro.

Através da modulação do suporte e da repetição das lâmpadas, procedimentos fiéis ao espírito industrial, Castiglioni não só recupera como até ultrapassa, em sua "flor-de-luz", as dimensões e a exuberância de estímulos visuais do lustre tradicional, agregando à simbologia antiga a almejada componente de contemporaneidade. De quebra, o recurso do "dimmer" possibilitando infinitas opções de intensidade de luz, algo impensável em qualquer época passada.

\section{Ruído Luminoso (microarqueologia projetual)}

Em paralelo ao consagrado Salone del Mobile di Milano, o grupo Zeus tem promovido nos últimos anos a mostra DEA - Design Europeo Anteprima, da qual 
tomam parte projetistas das mais variadas origens e correntes, convidados pela direção a elaborar trabalhos a partir de um tema dado. Em sua sétima edição. o tema formulado foi La strada delle cose - da dove... per dove. A luminária "zoom-zoom" (Fig. 3) é o resultado da tentativa de desenvolvê-lo, em parceria com Fabio Falanghe, atendendo ao gentil convite do arq. Maurizio Peregalli, curador da mostra.

De início, optou-se por interpretar "la strada delle cose" como sinônimo de fluxo das idéias, ou seja, percurso projetual. Em outras palavras, um convite à prática da metalinguagem. Dado este primeiro passo, tornou-se praticamente impositivo o desenvolvimento de um projetor ("da dove... per dove") de luz, em virtude da dupla metáfora projetor/projeto, luz/idéia, percurso e objetivo sintetizados num único objeto.

Da mesma forma que "o significado de um signo é outro signo" (Peirce), o significado de uma idéia é uma outra idéia lo surgimento de cada idéia entendido como resultado de curto-circuitos presentificadores da memória, admitindo, portanto, posteriores operações de "arqueologia" repertorial). Optou-se, então, por construir uma espécie de "bricolagem" de referências projetuais. De um lado, englobando elementos ópticos correlatos à idéia de projetor (lanterna, lupa, luneta). De outrolado, em claro aceno à condição terceiro mundista de antropófagos culturais, recorrendo à citação/homenagem de trabalhos consagrados (Achille Castiglioni, Roy Fleetwood, Shigeru Uchida).

A este ponto caberia tentar passar da presentificação do passado à exploração do território do possível.

A desconstrução (metáfora metalingüística) de um projetor convencional, explicitando-lhe os componentes, oferece-os à manipulação lúdica do receptor. Recupera-se, assim, tanto a idéia de criação como jogo, quanto a relação entre ruído (zumzum...) e informação (sempre presente no processo criativo), esta última acentuada pela utilização de filtros (des)qualificadores do facho luminoso.

\section{Bibliografia}

BENJAMIN, Walter. Obras escolhidas. São Paulo: Brasiliense, 1993. v. I.

CIRLOT, Juan-Eduardo. Dicionário de símbolos. São Paulo: Moraes, 1984.

GAGNEBIN, Jeanne Marie. Walter Benjamin. São Paulo: Brasiliense, 1982.

JAKOBSON, Roman. Lingǘstica e comunicação. São Paulo: Cultrix, s/d.

KOTHE, Flavio R. A alegoria. São Paulo: Ática, 1986. Princípios 72.

PIGNATARI, Décio. Semiótica e literatura. São Paulo: Cortez e Moraes, 79.

\footnotetext{
- Artigo elaborado a partir de fragmentos do trabalho final apresentado para a disciplina AUP-826 Mensagens Visuais Integradas, sob a orientação da Prof" Dr Élide Monzeglio, no 1ำ semestre de 1993.
} 